Title: A High Power Accelerator Driver System for Spallation Neutron Sources

Author(s):

Submitted to:

\section{Los Alamos}

NATIONAL LABORATORY
Andrew Jason, AOT-1

Barbara Blind, AOT-1

Paul Channell, AOT-1

Robert Garnett, AOT-6

John Gilpatrick, AOT-1

Edward Gray, AOT-1

1.OBg

John Lyles, AOT-5

Michael Lynch, AOT-5

Filippo Neri, AOT-1

Lawrence Rybarcyk, AOT-6

Robert Shafer, AOT-1

Ralph Stevens, AOT-2

Alan Wadlinger, AOT-1

Peter Walstrom, AOT-1

Thomas Wangler, AOT-1

Lloyd Young, AOT-1

DOE Office of Scientific and Technical

Information (OSTI)
JuL 19098

\&

Los Alamos National Laboratory, an aftirmative action/equal opportunity employer, is operated by the University of Calfomia for the U.S. Department of Energy under contract W-7405-ENG-36. By acceptance of this article, the publisher recognizes that the U.S. Government retains a nonexclustve, royaltyIree license to publish or reproduce the published form of this contrbution, or to allow others to do so, for U.S. Government purposes. The Los Alamos

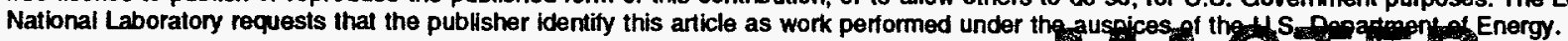




\section{DISCLAIMER}

Portions of this document may be illegible in electronic image products. Images are produced from the best available original document. 


\title{
A High Power Accelerator Driver System for Spallation Neutron Sources
}

\author{
Andrew Jason*, Barbara Blind, Paul Channell, Robert Garnett, John Gilpatrick, \\ Edward Gray, John Lyles, Michael Lynch, Filippo Neri, Lawrence Rybarcyk, Robert Shafer, \\ Ralph Stevens, E. Alan Wadlinger, Peter Walstrom, Thomas Wangler, and Lloyd Young
}

\begin{abstract}
This is the final report of a two-year, Laboratory-Directed Research and Development (LDRD) project at the Los Alamos National Laboratory (LANL). For several years, the Los Alamos Meson Physics Facility (LAMPF) and the Proton Storage Ring (PSR) have provided a successful driver for the nearly 100-kW Los Alamos Neutron Scattering Center (LANSCE) source. We have studied an upgrade to this system. The goal of this effort was to establish a credible design for the accelerator driver of a next-generation source providing $1-M W$ of beam power. We have explored a limited subset of the possible approaches to a driver and have considered only the low 1-MW beam power. The next-generation source must utilize the optimum technology and may require larger neutron intensities than we now envision.
\end{abstract}

\section{Background and Research Objectives}

Neutron scattering plays an important role in probing the structure of liquids and solids for both fundamental research and industrial research and development. A pulsed source of neutrons suitable for this purpose has been constructed at Los Alamos and is known as the Los Alamos Neutron Scattering Center (LANSCE). This facility utilizes the Los Alamos Meson Physics Facility (LAMPF) linac to accelerate a beam of negatively charged hydrogen ions to an energy of $800 \mathrm{MeV}$ in $700-\mu$ s pulses with a repetition rate of $20 \mathrm{~Hz}$. Each beam pulse is injected into the Proton Storage Ring (PSR) by charge-changing injection to produce a proton pulse less than $300 \mathrm{~ns}$ long. Immediate extraction and transport to a target produces an intense burst of neutrons useful for materials studies. The average proton-beam power is approximately $80 \mathrm{~kW}$. The short-pulse nature of such a source provides a complimentary facility to a reactor neutron source, such as the 55-MW Grenoble reactor or the proposed 330MW Advanced Neutron Source (ANS), accessing high-momentum-transfer interactions and short time scales beyond the low-energy and dc reactor capabilities.

* Principal investigator, e-mail: ajason@lanl.gov 
Recent attention has been given in Europe and the U.S. to the design of a neutron source with more than an order-of-magnitude-higher beam power than LANSCE. A Los Alamos study has accordingly concentrated on a design for a 1-MW source. The resulting scenario utilizes the side-coupled linac portion of LAMPF (constituting $90 \%$ of the linac) and a large part of the existing LAMPF infrastructure. The linac front end is modified and a new accumulator ring, target system, and research facility are additionally proposed. Such a source has been the thrust of this study into this year.

More recently, congressional action has omitted the ANS project from the national budget and given a mandate to Oak Ridge National Laboratory to conduct a study for a shortpulse spallation source (SPSS), such as we have proposed. In reaction to this, we note that SPSS will not be constructed for many years and that the cancellation of the ANS has created a research niche that can be filled by an accelerator at low cost. Specifically, the study was shifted to consideration of a long-pulse mode (LPSS) that does not require an accumulator ring, but rather takes the output of the LAMPF linac directly to a spallation target with pulse length of $1 \mathrm{~ms}$ (at $60 \mathrm{~Hz}$ repetition rate) rather than the much shorter SPSS pulse. The neutron brightness produced is equivalent to a 250-MW reactor. Exploitation of this brightness with appropriate instrumentation can lead, for most low-energy applications, to a source nearly equivalent to the ANS at substantially lower cost.

The objectives of the study, initially directed toward refining and diversifying the SPSS study, were shifted to the LPSS concept. Here the goal was to determine, in coordination with a parallel target study, the adaptability of the LAMPF linac to the current/time structure required by the LPSS and to devise a scheme for beam transport to the LAMPF area-A target location.

\section{Importance to LANL's Science and Technology Base and National R\&D Needs}

This project supports Los Alamos core competencies in nuclear science, plasmas, and beams as well as complex experimentation and measurement. Additionally, the study will increase the Laboratory's capabilities in accelerator technology. The eventual construction of the facility would contribute to the competency of nuclear and advanced materials. Such a facility would attract researchers in material sciences from universities, industry, and other Laboratories. The facility would also be synergistic with other Laboratory goals, particularly in the production of neutrons for a target facility, waste disposal, and tritium production. The importance to national goals is seen from the conclusions of high-level DOE-chartered panels that have emphasized the importance of a new U.S. source. This initiative would provide U.S. 
researchers with a greatly enhanced neutron-scattering facility for advanced-materials work as well as for achieving better understanding of the condensed-matter state.

\section{Scientific Approach and Results to Date}

Initially the study concentrated on completing the previous year's effort on the SPSS study and in extending the study to higher beam powers and alternative methods for producing the desired beam to the spallation target. Particularly, in the area of the linac, two conclusions were reached:

1. The higher observed loss of $\mathrm{H}^{-}$beam in the linac was entirely explainable by its construction and variations of the tuning parameters. There was no unknown mechanism for loss and such loss could be avoided using the lessons learned. This was accomplished by extensive simulations and reference to previous operations and experience.

2. The previous assertion that the linac could perform to the 1-MW specifications with replacement of the front end was further substantiated. However, the ultimate current carrying capacity of the linac could not meet the 5-MW goal without replacement of the side-coupled cavity linac (SCL). This conclusion was arrived at by experimental work during a linac development period and by comparison with simulations and previous operational experience. Additionally, a model was developed for the linac for use in the codes that allow better simulation of the linac. This was particularly valuable in the LPSS section of the study.

Ring studies included work on the relative merits of an accumulator ring approach versus a synchrotron-based concept. Were it not for the already existing infrastructure, the synchrotron would be less expensive at the 1-MW level. However, the accumulator ring would likely be more successful in meeting project goals, particularly in terms of beam loss and activation. This also appears to be the conclusion of the European spallation source study. Work was done on increasing beam capture efficiency over standard techniques and in adapting to the fast cycling rate in order to improve the viability of the synchrotron concept.

The LPSS study became of importance early in the year. The work was based on 1$\mathrm{MW} \mathrm{H} \mathrm{H}^{+}$beam power delivered to the spallation target with macropulses of $1.0 \mathrm{~ms}$ length and $60 \mathrm{~Hz}$ repetition rate. This implies a peak output current of nearly $21 \mathrm{~mA}$. Interlaced PSR operation at from 20 to $60 \mathrm{~Hz}$ and WNR operation as requested was required. After extensive simulation and drawing on operational experience it was concluded that the limitation in achieving reliable operation with low equipment activation, under these beam requirements, stems from four major causes: 
1. Limitations in the present $201.25-\mathrm{MHz}$ rf system. The present system cannot provide the required peak power at the required duty factor.

2. The inability of the low-energy beam transport (LEBT) bunching system to provide a clean longitudinal match to the drift-tube linac (DTL) causing subsequent losses in the transition region (TR) and SCL. Such losses increase rapidly with peak current and would result in very high activation for the peak-current levels here proposed.

3. The lack of provision for longitudinal matching of the TR to the linac.

4. The speed of the 805-MHz control loops in the SCL rf system. Substantial loss is generated by the macropulse turn-on transient.

To achieve the required performance with low loss, high reliability and operational ease, the following measures are recommended:

1. Replace the present injectors and DTL first tank with a 201.25-MHz Radio-Frequency Quadrupole (RFQ) linac to accelerate to an energy of $5.395 \mathrm{MeV}$. The $\mathrm{H}^{+}$and $\mathrm{H}^{-}$ beams are focused, chopped, and merged by a new LEBT at $100 \mathrm{keV}$ before the RFQ. A two-buncher matching section is placed after the RFQ. This arrangement produces the appropriate transverse and longitudinal match to the second tank of the DTL.

2. Replace the $201.25 \mathrm{MHz}$ rf system with a modern version that will produce adequate peak and average power.

3. Install an $805-\mathrm{MHz}$ bunch rotator cavity in the TR that will provide a good longitudinal match to the SCL.

4. Upgrade the low-level $\mathrm{rf}$-control system on SCL for operational ease and removal of initial transient loss on the macropulse.

5. An upgraded set of beam-diagnostic systems.

6. Provide transport to the LPSS target with a nonlinear expander to give a hard-edged beam spot on the target.

7. Install a laser system in Line D that neutralizes $\mathrm{H}$ - beam to provide for WNR operation. 8. A computer control system upgrade in support of the modifications.

With these modifications, a peak beam current of more than $25 \mathrm{~mA}$ can be supplied to the LPSS target to provide over 1.2 MW of beam power delivered at $60 \mathrm{~Hz}$ with a $1.0-\mathrm{ms}$ macropulse length. A schematic drawing of the modified linac is shown in Figure 1.

Issues in this scenario include the ability to chop for PSR operation at low energy. A separate study has been launched to look into this aspect. Additionally, the laser chopping in Line D may require more development than anticipated.

A less expensive alternative has been also discussed that will not provide such high performance. If adequate bunching can be done by the addition of harmonics in the present low-energy beam line, the expensive RFQ, the low-energy chopper, and the laser neutralization 
can be dispensed with. A position paper using this scenario and providing scientific justification for the project has been written to be evaluated by the neutron scattering community.

\section{Publications}

Jason, Andrew, "The Los Alamos Study for a Next Generation Spallation-Neutron Source Driver," in Proceedings of the Fourth European Particle Accelerator Conference, London, 3, 2684, (1994), Los Alamos Report LAUR \#94-2161.

Jason, Andrew; Blind, Barbara; Wang, Tai-Sen; and Channell, Paul; "Minimization of FirstTurn Losses by Excited Neutrals in Charge-Changing Injection of Accumulator Rings," in Proceedings of the Fourth European Particle Accelerator Conference, London, 2, 1219 , (1994), Los Alamos Report LAUR \#94-2195.

Jason, Andrew, et al., "Accelerator, Accumulator, and Beam Transport," in "Los Alamos Next-Generation Spallation Source," volume 1, section 2, pp 2-1 to 2-225, Los Alamos Report LAUR \#95-4300.

Barlow, David; Jason, Andrew; Neri, Fillipo; and Walstrom, Peter, "Mirror-Field Magnet for Stripped Electron Sweeping," to be published in IEEE Transactions on Magnetics, Los Alamos Report LAUR \#95-1851.

Garnett, Robert; Gray, Edward; Rybarcyk, Lawrence; and Wangler, Thomas, "Simulation Studies of the LAMPF Proton Linac," invited paper, to be published in Proceedings of the 1995 Particle Accelerator Conference, Dallas, May 1995, Los Alamos Report LAUR \#951453.

Jason, Andrew, "Linac-Driven Spallation-Neutron Source," invited paper, to be published in Proceedings of the 1995 Particle Accelerator Conference, Dallas, May 1995, Los Alamos Report LAUR \#95-1566.

\section{DISCLAIMER}

This report was prepared as an account of work sponsored by an agency of the United States Government. Neither the United States Government nor any agency thereof, nor any of their employees, makes any warranty, express or implied, or assumes any legal liability or responsibility for the accuracy, completeness, or usefulness of any information, apparatus, product, or process disclosed, or represents that its use would not infringe privately owned rights. Reference herein to any specific commercial product, process, or service by trade name, trademark, manufacturer, or otherwise does not necessarily constitute or imply its endorsement, recommendation, or favoring by the United States Government or any agency thereof. The views and opinions of authors expressed herein do not necessarily state or reflect those of the United States Government or any agency thereof. 


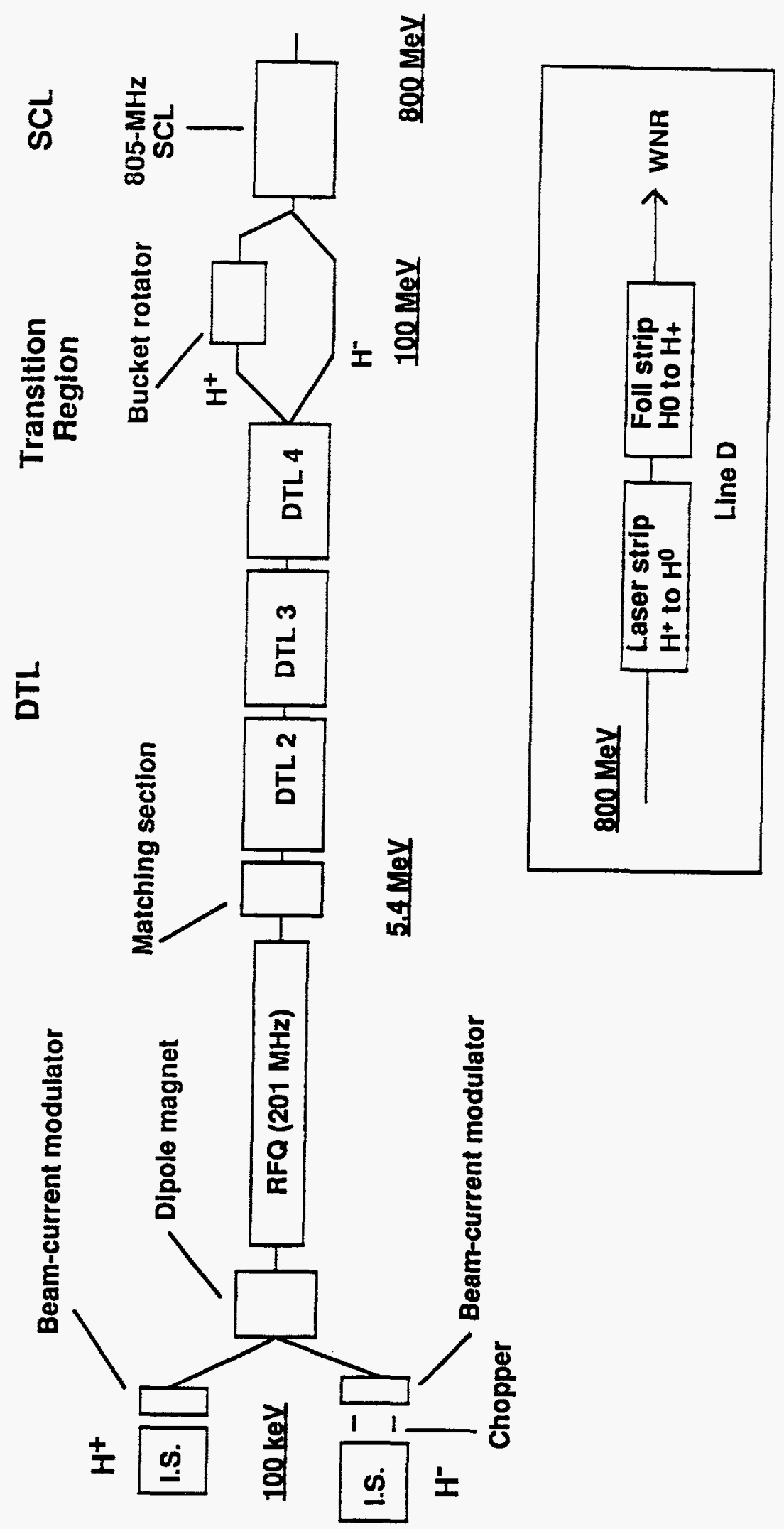

Fig 1. Schematic of the recommended linac modifications to implement the LPSS. The inset shows addition of a laser system to Line D for chopping the beam to WNR. 